\title{
PREVODI SLOVENSKE KNJIŽEVNOSTI V NOVO GRŠČINO ZAPIS PREVAJALKE
}

Small is beautiful. To reklo mi v spomin vsakič znova prikliče mojo ljubljeno Slovenijo: tako majhna in tako lepa dežela, tako 'majhen' in tako lep jezik. Jezik, ki sem ga prvič slišala v zibelki: zven, glasovi, melodičnost samoglasnikov in soglasnikov (še posebej soglasnikov) v blaženosti brezkrajne čutnosti.

Osem let kasneje sem govorila drug jezik, grški, jezik starodavnih korenin, ki segajo vse do jezika-maternice evropske misli, do jezika-mita: do stare grščine.

Slovenščino bi skoraj pozabila. A k sreči ona ni pozabila name. Prišla je v podobi grecista Marijana Tavčarja in me našla v Gledališki šoli Grškega nacionalnega gledališča, kjer sem se tedaj šolala. Marijan Tavčar je bil navezal prijateljske stike z enim od mojih profesorjev, znamenitim zgodovinarjem - teatrologom Jannisom Siderisom, ki je vesel, da mu lahko predstavi tako redek sadež - slovensko-grško študentko -, poskrbel, da sva se spoznala. Pregovoril me je, naj se lotim prevoda romana Ne bog ne žival Kajetana Koviča, ki ga je v sedemdesetih letih izdala založba Alvin Redman Hellas (žal nimam ob sebi nobenega izvoda, da bi se prepričala o natančni letnici izida).

Mislim, da je delo Ne bog ne žival prvi slovenski roman, ki je izšel v Grčiji. Po zaslugi tega prevoda sem se začela posvečati svojemu prvemu maternemu jeziku in se ga ponovno naučila. In ko sem se kasneje vzporedno z delom v gledališču sistematično ukvarjala s prevajanjem zlasti iz francoskega jezika, sem si po svojih najboljših močeh prizadevala tudi za prevode slovenskega leposlovja. Ne pozabimo, da je bila v tistih časih Slovenija za Grke tako rekoč terra incognita - da ne omenjam, da je tako nemara tudi še dandanes. Kakorkoli že, grško bralstvo je dobilo priložnost seznaniti se z vrsto slovenskih pesnikov in pisateljev:

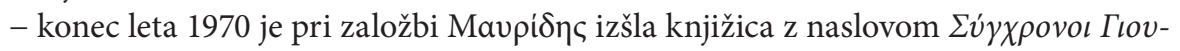

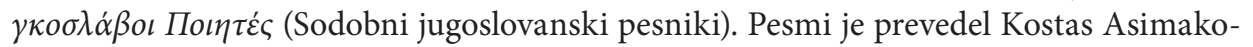
poulos, ki je napisal tudi predgovor in komentar. V antologiji so predstavljeni trije slovenski pesniki: Matej Bor, Dane Zajc in Kajetan Kovič;

- leta 1972 je založba $\Delta \omega \delta \varepsilon \dot{k} \alpha \tau \eta$ ' $\Omega \rho a$ izdala manjšo antologijo z naslovom $A v \theta o$ -

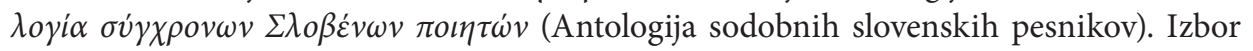
pesmi in prevod sta delo Marijana Tavčarja. Antologija prinaša pesmi Srečka Kosovela, Alojza Gradnika, Mirana Jarca, Antona Vodnika, Edvarda Kocbeka, Boža Voduška, Maričke Žnidaršič, Mileta Klopčiča, Jožeta Udoviča, Mateja Bora, Ceneta Vipotnika, Jožeta Šmita, Janeza Menarta, Franceta Balantiča, Karla Destovnika - Kajuha, Cirila Zlobca, Branka Hofmana, Petra Levca, Ivana Minattija, Lojzeta Krakarja, Daneta Zajca, Gregorja Strniše, Kajetana Koviča, Vena Tauferja, Saše Vegrija in Tomaža Šalamuna; 
- nekoliko kasneje je izšel še prevod pesniške zbirke Maričke Žnidaršič Nalomljena veja (žal ne vem, pri kateri založbi);

- leta 1981 je Jannis G. Benekos pri založbi Níкоৎ Bótonৎ izdal Antologijo balkanske

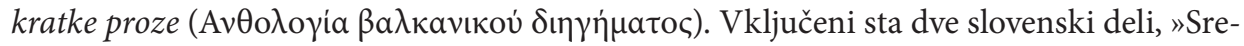
ča " Cirila Kosmača in »Grob « Andreja Hienga;

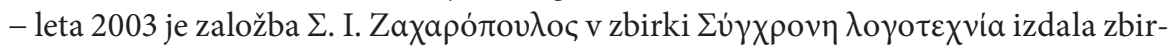
ko novel Andreja Blatnika, Igorja Bratoža, Evalda Flisarja, Branka Gradišnika, Draga Jančarja, Uroša Kalčiča, Milana Kleča, Marta Lenardiča, Vinka Möderndorferja, Andreja Moroviča, Maje Novak, Rudija Šelige, Alekse Šušulič in Janija Virka. Zbirka nosi naslov

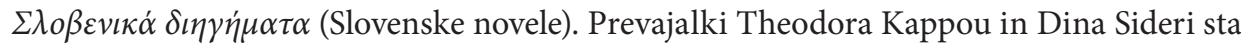
se naslanjali na angleške in nemške prevode;

- Dina Sideri je iz angleščine prevedla tudi roman Evalda Flisarja Sanje mojega oče-

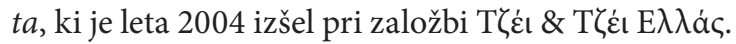

V grški javnosti najbolj znani slovenski pisec je seveda filozof Slavoj Žižek s svojim obširnim opusom. Do danes so v Grčiji pri založbi Scripta izšli prevodi petih njegovih knjig: The puppet and the dwarf: The perverse Core of Christianity, Welcome to the Desert of the Real: Five Essays on September 11 and Related Dates, Did Somebody say Totalitarianism: Five Interventions in the (Mis) Use of a Notion, Iraq: The Borrowed Kettle in The Sublime Object of Ideology. Kot je razvidno iz naslovov izvirnikov, so bila dela prevedena iz angleščine.

Sama seveda prevajam dosledno iz slovenščine, a sem na žalost $\mathrm{v}$ tem trenutku $\mathrm{v}$ Grčiji najbrž edina. Poleg romana Ne bog ne žival sem v grščino prevedla tri knjige Kajetana Koviča, namenjene najmlajšim bralcem, in sicer Mačka Murija, Zmaja Direndaja

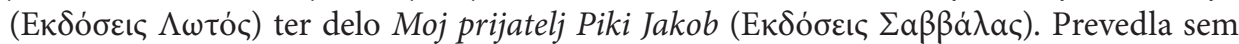

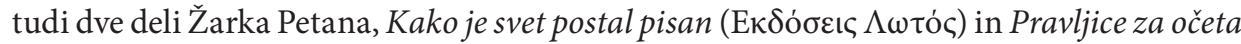

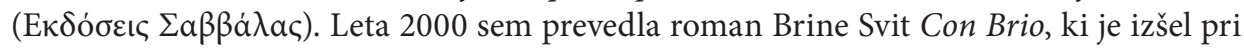
založbi Пaтáknฺ.

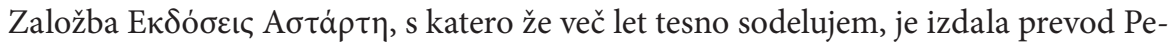
tanovega Veselega Diktatorja, pa tudi dve knjigi njegovih aforizmov (v mojem prevodu). Prav pred kratkim pa je pri isti založbi izšel še roman Tite Kovač - Artemis Grški feniks (prav tako v mojem prevodu). Gre za biografijo Joannisa Kapodistriasa, predsednika prve grške vlade in utemeljitelja novogrške države, čigar poreklo sega v Koper, Capo d'Istria.

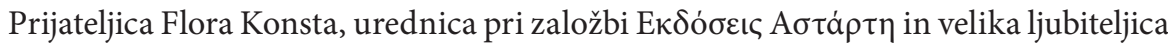
Slovenije, njene narave, kulture in književnosti, mi je predlagala, naj v grščino prevedem nekaj najbolj značilnih črtic Ivana Cankarja, da bi tudi Grki spoznali tega velikega slovenskega književnika. To je seveda tudi moja velika želja in upam, da bo kmalu doživela uresničitev. Prav tako upam, da mi bo uspelo še nekaj, kar se mi zdi izredno pomembno: prepričati kvalitetno grško gledališko skupino, da bi na oder postavila dramsko delo Draga Jančarja Zalezujoč Godota, katerega prevod sem že končala.

Zapisa o izdajah slovenskega leposlovja v Grčiji ne bi hotela zaključiti, ne da bi omenila nekaterih predstavitev $\mathrm{v}$ grški periodiki.

Zelo pomembna literarna revija $\dot{\eta} \lambda \dot{\varepsilon} \xi \eta$ je v dveh številkah objavila izbor pesmi Kaje-

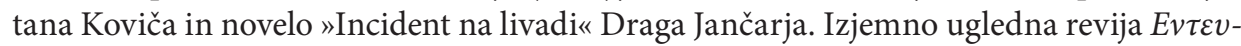
$\kappa \tau \dot{\eta} \rho \iota$, ki izhaja v Solunu, pa je objavila pesmi Žarka Petana in Vena Tauferja. Prevodi 
Kovičevih in Petanovih pesmi ter Jančarjeve novele so moje delo, medtem ko je poezijo Vena Tauferja prevedel njegov grški prijatelj, pesnik in pisatelj Anastasis Vistonitis.

Seveda je ta kratki zapis zelo omejen tako po vsebini (navajam zgolj tisto, kar mi je slučajno znanega o prevodih slovenske poezije in proze $\mathrm{v}$ grščino) kot po časovnem obdobju, ki ga pokriva (okrog štirideset let). Upam, da bomo nekoč dobili natančnejšo in popolnejšo bibliografijo prevodov slovenske književnosti v grški jezik.

Lojzka Avajanos

\section{SEZNAM PREVODOV SLOVENSKIH AVTORJEV V NOVOGRŠKI JEZIK}

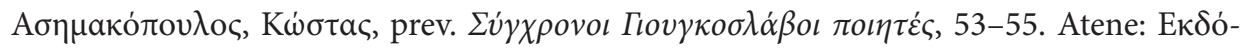

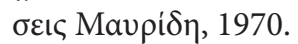

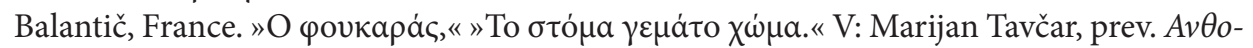

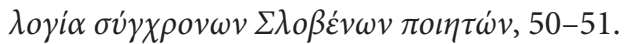

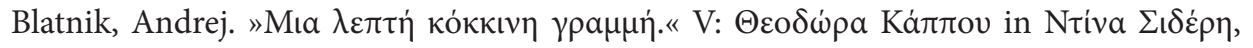

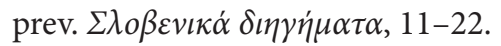

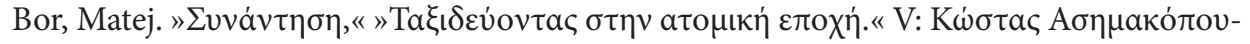

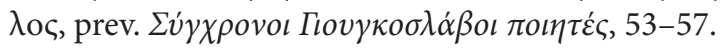

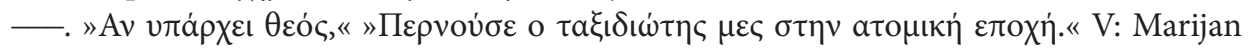

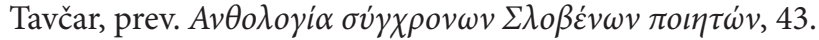

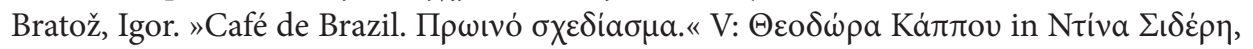

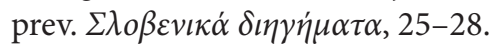

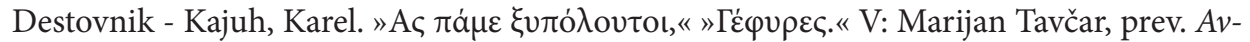

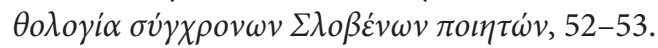

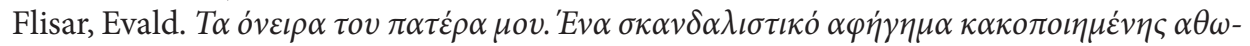

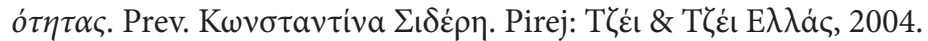

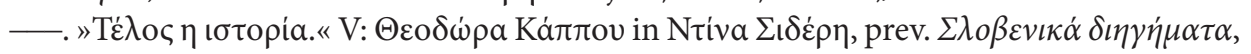
31-54.

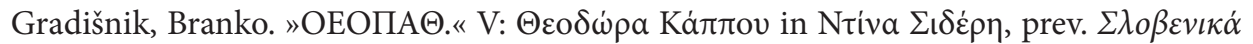
$\delta\llcorner\eta \gamma \eta \dot{\mu} \alpha \tau \alpha, 57-70$.

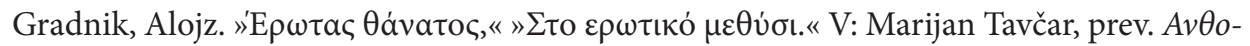

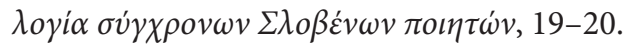

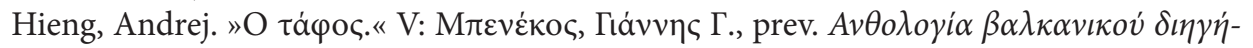

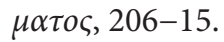

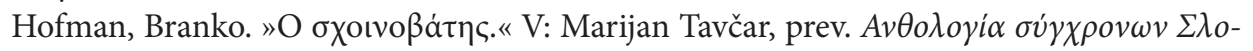
$\beta \varepsilon \dot{\varepsilon} v \omega v \pi \circ \eta \eta \tau \dot{\omega} v, 56$.

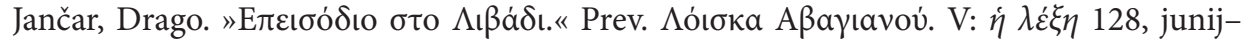
avgust 1995, 554-59.

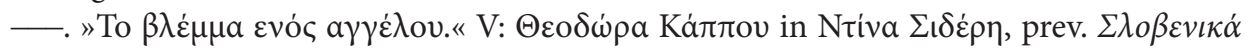
$\delta ı \eta \gamma \dot{\eta} \mu \alpha \tau \alpha, 73-84$.

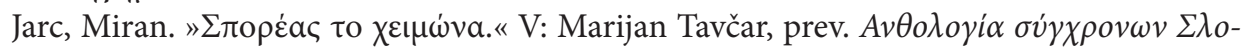

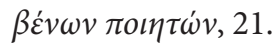




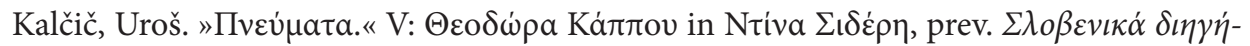
$\mu \alpha \tau \alpha, 87-110$.

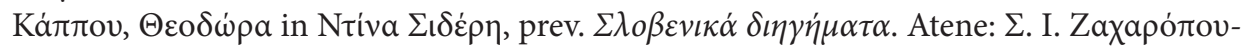
$\lambda$ 入c, 2003.

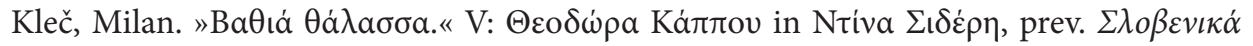
$\delta ı \eta \gamma \eta \mu \alpha \tau \alpha, 113-20$.

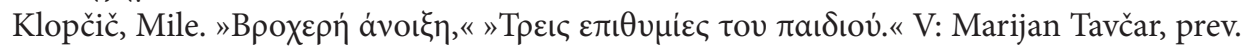

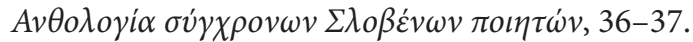

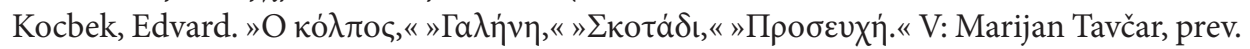

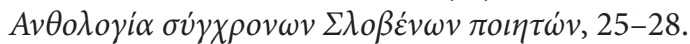

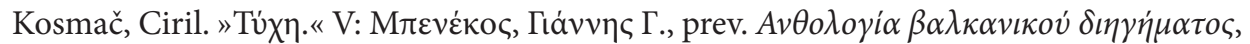
149-63.

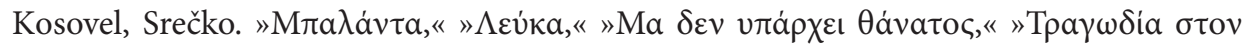

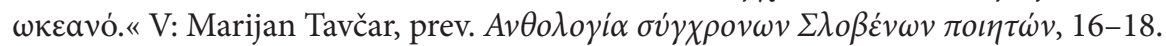

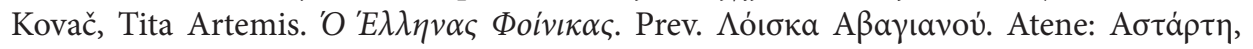
2008.

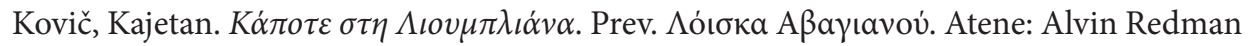
Hellas, 1970.

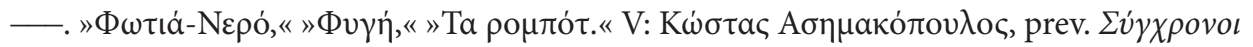

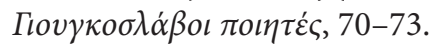

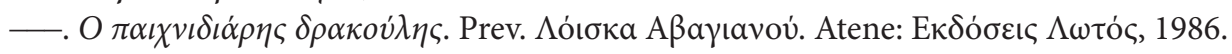

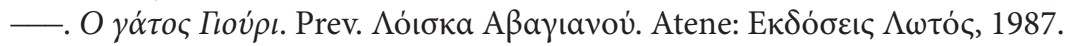

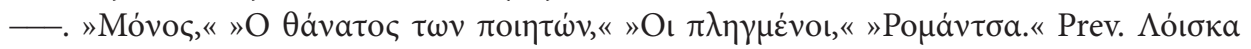
Aßaүıаvoú. V: $\dot{\eta} \lambda \dot{\varepsilon} \xi \eta$ 95, junij 1990, 419-21.

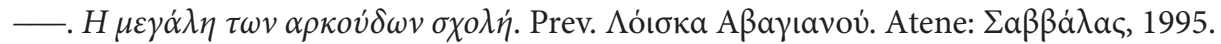

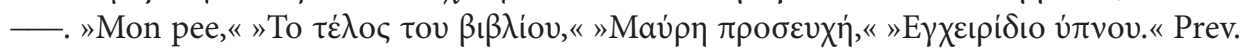

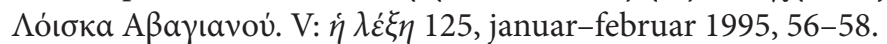

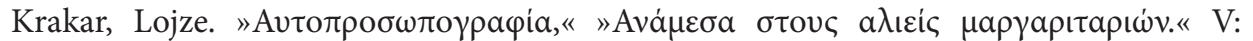

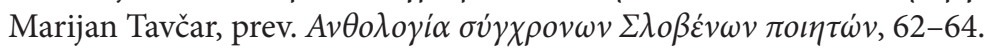

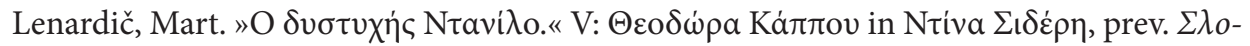

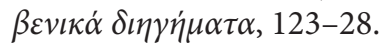

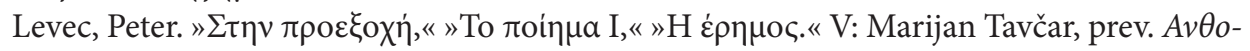

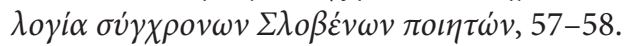

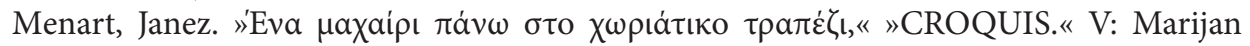

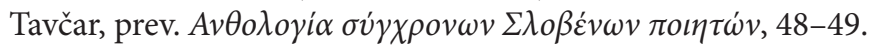

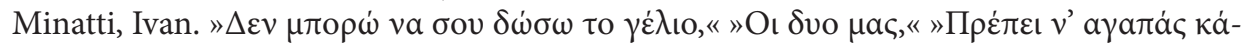

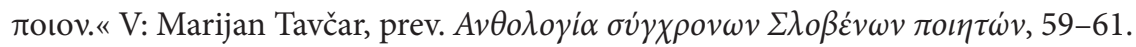

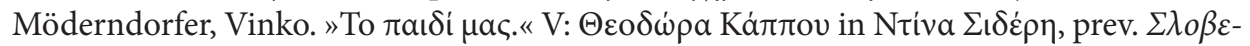

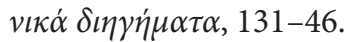

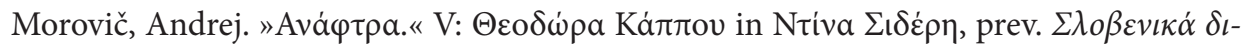
$\eta \gamma \eta \dot{\eta} \alpha \tau \alpha, 149-56$.

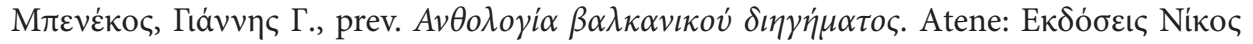

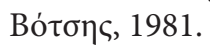




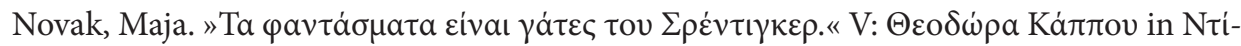

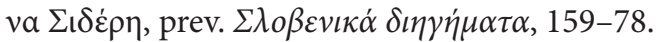

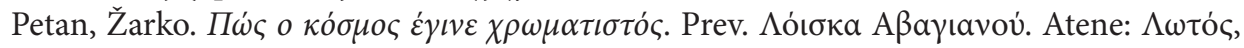
1986.

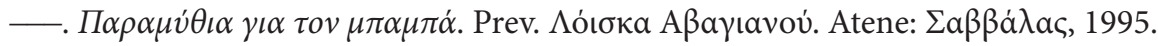

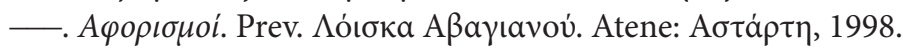

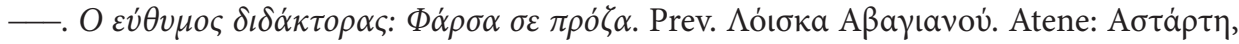
1998.

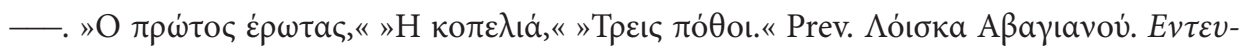

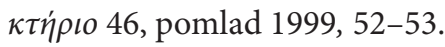

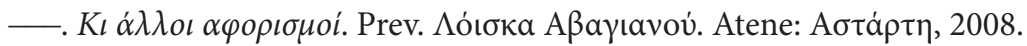

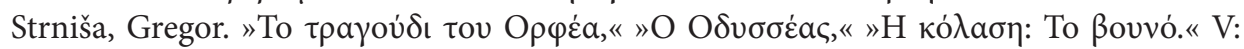

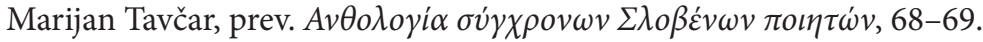

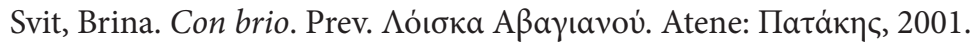

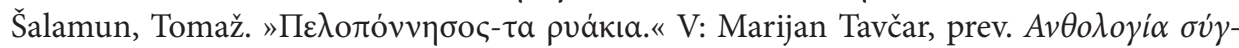
$\chi \rho o v \omega v \Sigma \lambda o \beta \varepsilon \dot{v} \omega v \pi \circ \imath \eta \tau \omega \dot{v}, 77$.

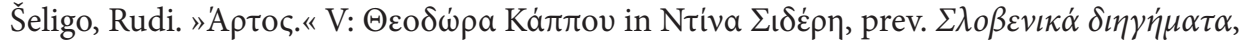
181-98.

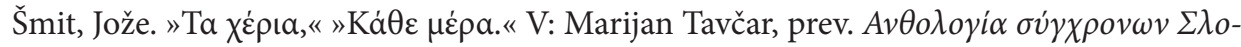
$\beta \dot{\varepsilon} v \omega v \pi o \iota \eta \tau \omega ́ v, 46-47$.

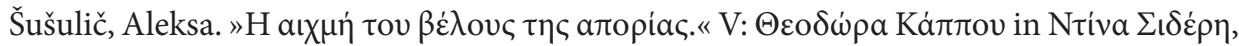

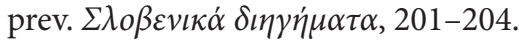

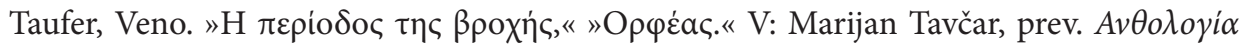
$\sigma \dot{\gamma} \chi \rho \circ v \omega v \Sigma \lambda \circ \beta \dot{\varepsilon} v \omega v \pi \circ \iota \eta \tau \dot{\omega} v, 75-76$.

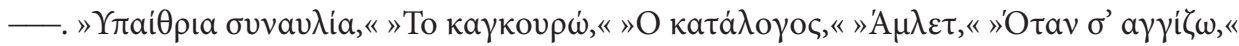

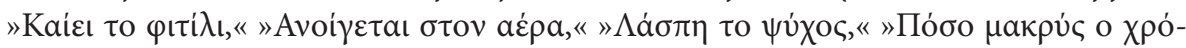

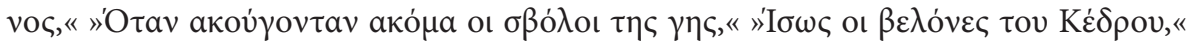

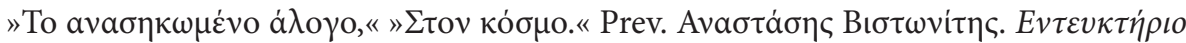
46, pomlad 1999, 45-51.

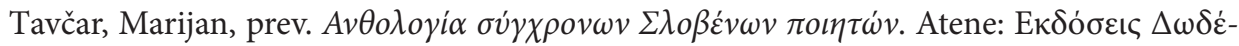

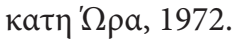

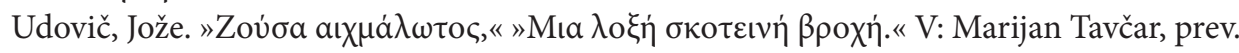

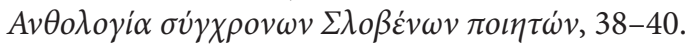

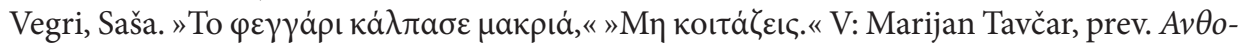

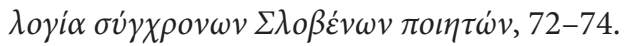

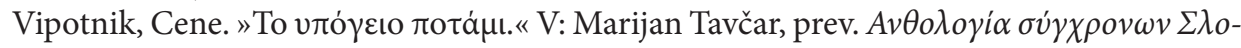
$\beta \dot{\varepsilon} v \omega v \pi o \imath \eta \tau \omega ́ v, 44-45$.

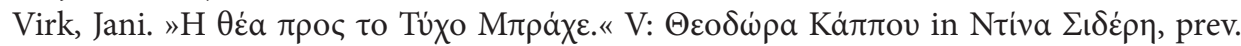

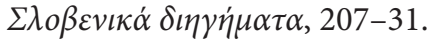

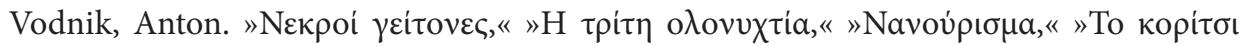

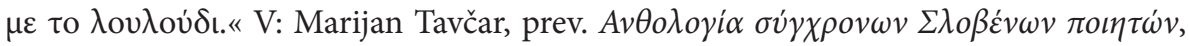
$22-24$.

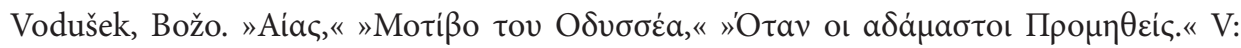

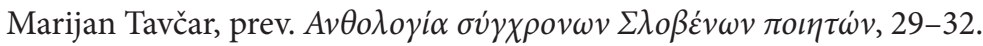




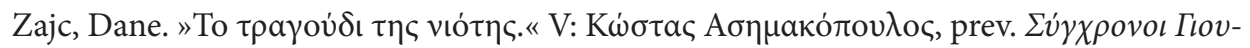

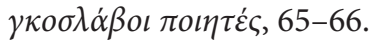

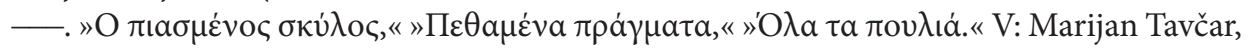

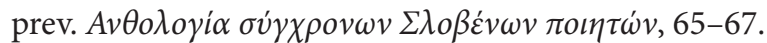

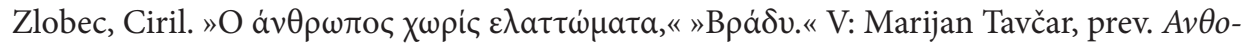

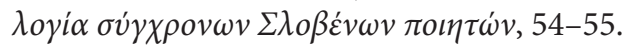

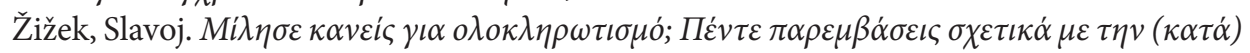

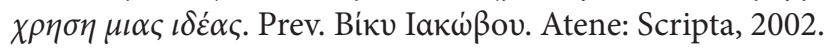

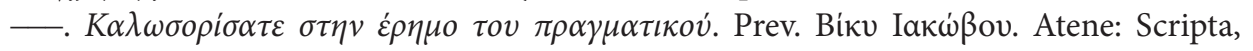
2003.

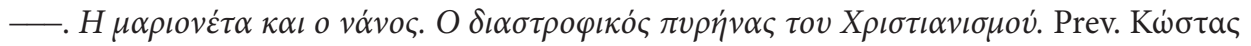

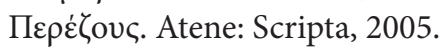

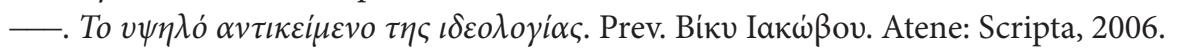

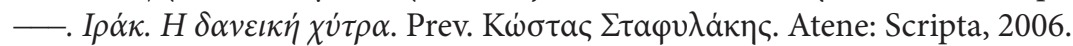

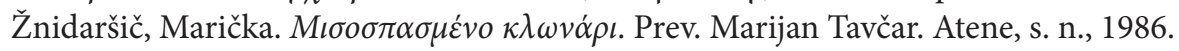

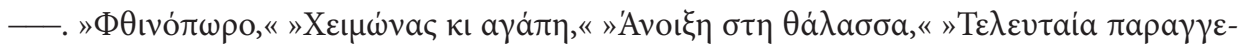

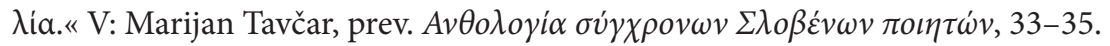

Bibliografski seznam V. V. in J. K. 